\title{
Endoscopic approach to complex gastric tube stricture after laparoscopic sleeve gastroplasty: a case report
}

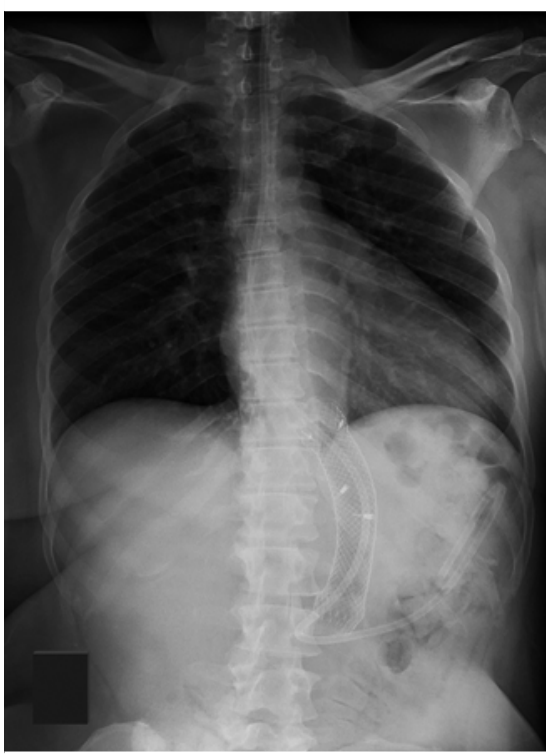

- Fig. 1 Fluoroscopic aspect after the first endoscopic stent placement.

As bariatric surgery becomes more prevalent, endoscopists commonly face adverse events now that this minimally invasive treatment has little morbidity and great efficacy [1]. Gastric tube stricture is one of the most common adverse events, occurring in 0.1 to $3.9 \%$ of patients [2,3]. Mechanical stricture (gastric sleeve) and axis deviation are the entities that can cause obstruction [2].

Endoscopic treatment often includes pneumatic balloon dilation and/or selfexpandable metal stent (SEMS) placement with great success rates $[3,4]$. Recently, endoscopic tunneled stricturotomy has been adopted as a promising technique [5].

We present a case ( $\downarrow$ Video 1 ) of a 55-year-old woman with morbid obesity (body mass index of $43.9 \mathrm{~kg} / \mathrm{m}^{2}$ ). She underwent a laparoscopic sleeve gastrectomy and developed progressive dysphagia in the follow-up. Upper gastrointestinal (GI) endoscopy and contrast $X$-ray image revealed gastric tube stricture and axis deviation.

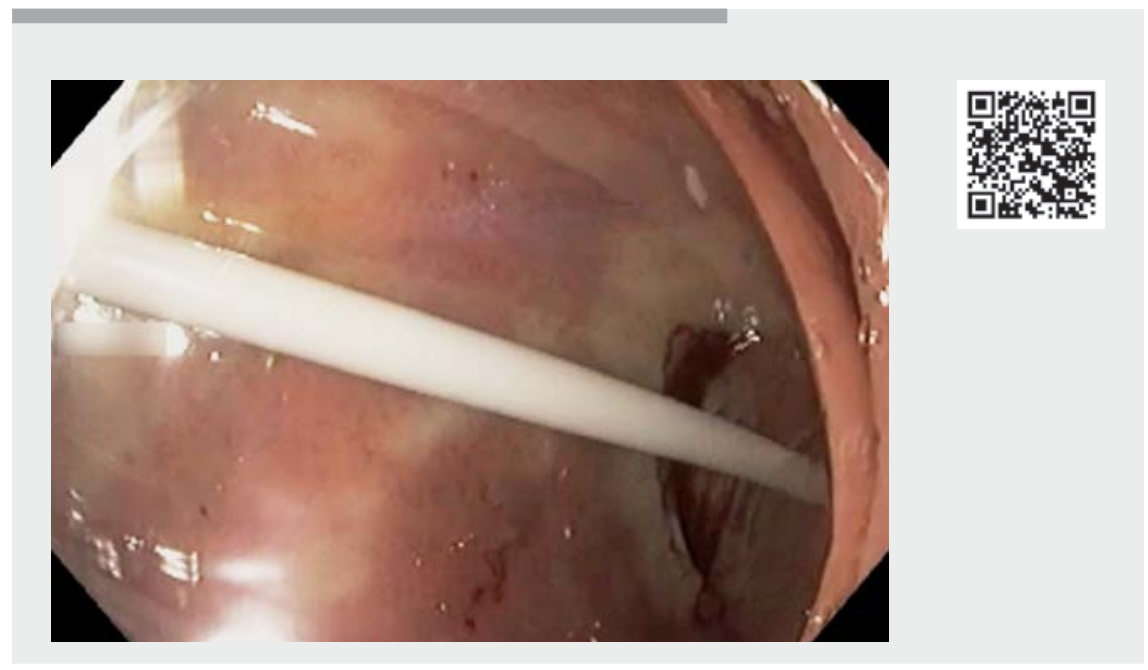

$\checkmark$ Video 1 Complex strictures after gastrointestinal surgery are challenging for endoscopic management. In this case report with video, we highlight different therapeutic endoscopic options that might be used in these cases.

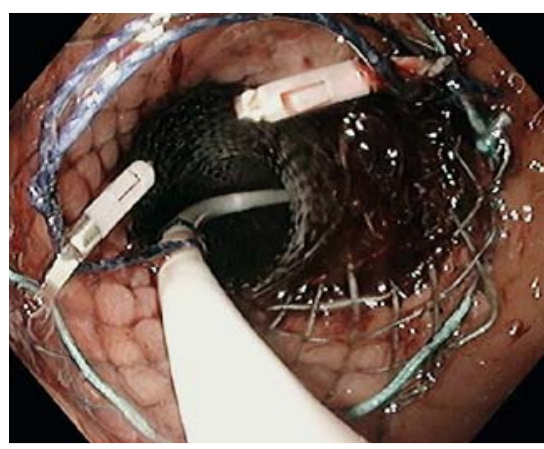

- Fig. 2 Self-expandable metal stent (SEMS) fixed to the nasoenteric catheter by suture threads and metallic clips to avoid stent migration.

An endoscopic tunneled stricturotomy with full-thickness dissection was performed 6 months after the surgery, although without technical or clinical success.

A new endoscopic approach was performed with pneumatic balloon dilation $(30 \mathrm{~mm})$ followed by placement of a $23 \times 105-\mathrm{mm}$ partially covered esophageal SEMS (PCSEMS) ( $\triangleright$ Fig. 1). To avoid stent migration, a nasoenteral feed tube

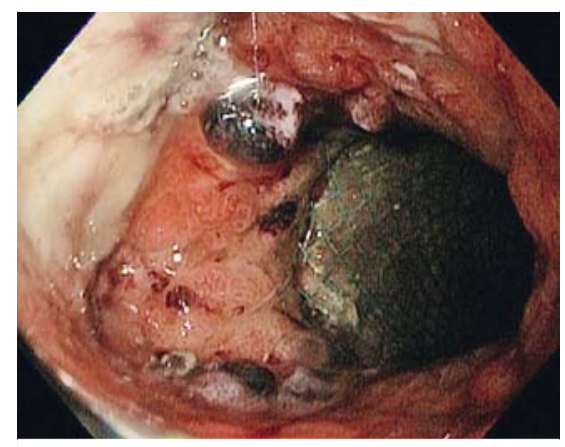

Fig. 3 Tissue hyperplasia in the proximal stent end (uncovered area), precluding its removal.

with suture threads was fixed to the stent using metallic clips ( $>$ Fig. 2 ). After this procedure, the patient improved clinically and tolerated a soft oral diet well.

At 18 days after placement, intense tissue hyperplasia in the proximal and distal portions of the stent (uncovered areas) made removal impossible ( $\mathbf{F i g . 3}$ ). So a $23 \times 155-\mathrm{mm}$ fully covered esophageal stent (FCSEMS) was placed over the first stent (stent-in-stent technique) ( Fig.4). After 1 week, the patient pre- 


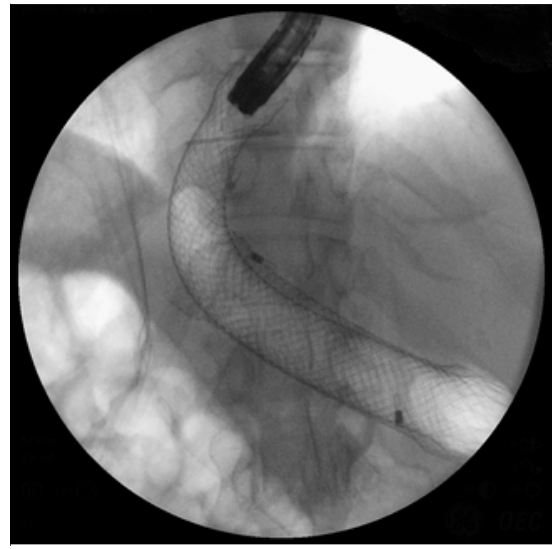

Fig. 4 Fluoroscopic aspect of the stentin-stent technique.

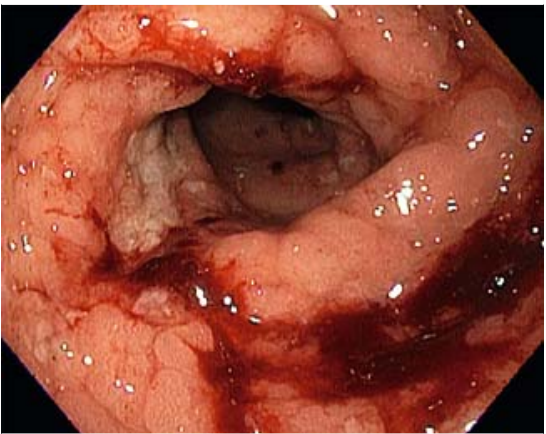

Fig. 5 Stricture area after the removal of both stents.

sented good acceptance of a soft oral diet and both stents were removed endoscopically without complications ( $>$ Fig.5). Currently (2.5 months after the last procedure), the patient remains with a good soft oral diet intake and stable weight. She is satisfied with the improvement in her quality of life and no further endoscopic intervention is necessary.

Endoscopy_UCTN_Code_TTT_1AO_2AH
Competing interests

The authors declare that they have no conflict of interest.

\section{The authors}

Mateus Pereira Funari ${ }^{\odot}$, Antônio Afonso Miranda Neto, Vitor Massaro Takamatsu Sagae, Thiago Ferreira de Souza, Maurício Kazuyoshi Minata ${ }^{\odot}$, Spencer Cheng, Eduardo Guimarães Hourneaux de Moura

Gastrointestinal Endoscopy Unit, Hospital das Clínicas da Faculdade de Medicina da Universidade de São Paulo, Brazil

\section{Corresponding author}

\section{Mateus Pereira Funari, MD}

Hospital das Clínicas da Faculdade de Medicina da Universidade de São Paulo, Division of Gastroenterology - Endoscopy Unit, Av. Dr. Enéas de Carvalho Aguiar, 255, Instituto Central - Prédio dos Ambulatórios Cerqueira César, São Paulo, SP, 05403-000, Brazil mateusfunari@gmail.com

\section{References}

[1] Deslauriers V, Beauchamp A, Garofalo F et al. Endoscopic management of post-laparoscopic sleeve gastrectomy stenosis. Surgical Endoscopy 2018; 32: 601-609

[2] Ogra R, Kini GP. Evolving endoscopic management options for symptomatic stenosis post-laparoscopic sleeve gastrectomy for morbid obesity: experience at a large bariatric surgery unit in New Zealand. Obesity Surgery 2015; 25: 242-248

[3] Okazaki O, Bernardo WM, Brunaldi VO et al. Efficacy and safety of stents in the treatment of fistula after bariatric surgery: a systematic review and meta-analysis. Obesity Surgery 2018; 28: 1788-1796
[4] Agnihotri A, Barola S, Hill C et al. An algorithmic approach to the management of gastric stenosis following laparoscopic sleeve gastrectomy. Obesity Surgery 2017; 27: 2628-2636

[5] de Moura EGH, de Moura DTH, Sakai CM et al. Endoscopic tunneled stricturotomy with full-thickness dissection in the management of a sleeve gastrectomy stenosis. Obesity Surgery 2019; 29: 2711-2712

Bibliography

Endoscopy 2021; 53: E396-E397

DOI 10.1055/a-1314-9094

ISSN 0013-726X

published online 17.12.2020

(c) 2020. Thieme. All rights reserved.

Georg Thieme Verlag KG, Rüdigerstraße 14 70469 Stuttgart, Germany

\section{ENDOSCOPY E-VIDEOS}

https://eref.thieme.de/e-videos

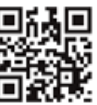

Endoscopy E-Videos is a free access online section, reporting on interesting cases and new

techniques in gastroenterological endoscopy. All papers include a high quality video and all contributions are freely accessible online.

This section has its own submission website at https://mc.manuscriptcentral.com/e-videos 